\title{
Vitamin D Receptor Agonists: Suitable Candidates as Novel Therapeutic Options in Autoimmune Inflammatory Myopathy
}

\author{
Clara Crescioli \\ Section of Health Sciences, Department of Movement, Human and Health Sciences, University of Rome Foro Italico, 00135 Rome, Italy \\ Correspondence should be addressed to Clara Crescioli; clara.crescioli@uniroma4.it
}

Received 27 December 2013; Accepted 9 April 2014; Published 7 May 2014

Academic Editor: Marina Bouché

Copyright (C) 2014 Clara Crescioli. This is an open access article distributed under the Creative Commons Attribution License, which permits unrestricted use, distribution, and reproduction in any medium, provided the original work is properly cited.

\begin{abstract}
The primary aim in the treatment of autoimmune inflammatory myopathies (IMs) is to recover muscle function. The presence of immune/inflammatory cell infiltrates within muscle tissues represents the common feature of different IM subtypes, albeit a correlation between muscular damage extent and inflammation degree is often lacking. Treatments for IMs are based on life-long immunosuppressive therapy, with the well known adverse effects; recovery is incomplete for many patients. More effective therapies, with reduced side-effects, are highly desirable. Vitamin D receptor (VDR) agonists emerge to retain pleiotropic anti-inflammatory properties, since they regulate innate and adaptive immunity by switching the immune response from proinflammatory $\mathrm{T}$ helper 1 (Th1) type to tolerogenic T helper 2 (Th2) type dominance. In skeletal muscle cells less hypercalcemic VDR ligands target powerful mediators of inflammation, such as TNF $\alpha$ and TNF $\alpha$ driven paths, without affecting immune or muscle cells viability, retaining the potentiality to counteract Thl driven overreactivity established by the self-enhancing inflammatory loop between immune and skeletal muscle cells. This review summarizes those features of VDR agonists as candidates in future treatment of IM.
\end{abstract}

\section{Introduction}

Increasing evidence points out that vitamin $\mathrm{D}$, beside bone metabolism and calcium homeostasis regulation, plays a pivotal role in maintaining the functionality of many other tissues, including skeletal muscle. A direct association of vitamin $\mathrm{D}$ status with skeletal muscle fiber composition, muscle power and force, or physical performance has been documented by several studies in old or young human population $[1,2]$; remarkably, vitamin $\mathrm{D}$ supplementation is associated with improvements in muscle performance and fall reduction $[1,3-6]$.

Experimental models of VDR null mutant mice document diffused muscle fiber abnormalities and severe alterations in muscle cell differentiation or fiber development/ maturation [7-9]; in humans, VDR gene polymorphisms have been associated with muscle strength defects, as recently reported $[1,10]$. Direct effects of vitamin D on muscle cell proliferation, differentiation, and myotube size have been recently proposed in a murine experimental in vitro model [11]. Skeletal muscle is a well known target tissue of vitamin $\mathrm{D}$ action and the association between severe vitamin $\mathrm{D}$ deficiency and myopathy has been recognized since and recently confirmed $[1,12]$. Myopathy is characterized by severe myofiber degeneration and muscle wasting; in particular, IMs are a wide range of autoimmune diseases, collectively known as myositis, characterized clinically by reduced muscle endurance and weakness, chronic inflammation, and infiltration by immune/inflammatory cells in skeletal muscles. Since both adaptive and innate immunity are involved in IMs, the mainstay treatment is directed to suppress or modify immune cell activity and is based on high dose corticosteroid combined with immunosuppressive drugs, as steroid-sparing agents [13-15]. However, most of IM patients have just a partial clinical improvement, few recover muscle performance, and about $25 \%$ are refractory to those drugs and left with disability [13-15], suggesting that pharmacological targeting the immune system may be not enough for satisfactory therapeutic effects.

Much more interest has been recently addressed to the muscular component, as an active counterpart dialoguing with the immune system during inflammation throughout 
the production of cytokines and chemokines, highly chemotactic peptides. In this light, skeletal muscle cells, behaving as immunoactive structures, could be also hypothesized to be therapeutic targets as well.

Advances in clinical and bench research highlight the vitamin D impact on muscle function and morphology, either in physiologic or pathologic conditions [16-18]; also, VDR agonists emerge to exert pleiotropic activities in (auto)immune regulation by targeting both immune and resident cells [1921].

This review aims to offer an overview on VDR agonists as potential novel therapeutic tools to control inflammation in IMs; in particular, biomolecular pathway(s) and inflammatory mediators within skeletal muscle cells engaged in IM pathogenesis, such as the cytokine TNF $\alpha$ and the chemokine CXCL10, will be discussed as intracellular pharmacological target(s) of nonhypercalcemic VDR agonists.

\section{Pathogenic Mechanisms of IMs}

IMs are a heterogeneous group of systemic autoimmune diseases subclassified in distinct subgroups, that is, idiopathic dermatomyositis (DM), polymyositis (PM), inclusion body myositis (IBM), the most studied ones, necrotizing autoimmune myositis, and myositis associated with systemic disorders on the basis of some clinical and histological differences [22-24]. Muscle weakness, fatigue, and elevated serum muscle enzymes, together with myofiber degeneration/fibrosis and mononuclear cell infiltration represent, respectively, clinical and histological features common to all subtypes.

Different pathogenic mechanisms have been hypothesized due to distinct predominating localization/phenotype of the inflammatory infiltrates, that is, while a striking dominance of $\mathrm{CD}^{+} \mathrm{T}$ cells has been reported at perivascular/perimysial sites, as often found in DM, endomysial infiltrates are dominated by $\mathrm{CD}^{+} \mathrm{T}$ cells, as more frequently observed in PM and IBM; the presence of B lymphocytes, which seem to preferentially target the microvascular component in DM, is considered less critical in PM [25]. Those differences, however, appear to be an oversimplification of the reality: an overlap between clinical phenotypes, immunotypes, and histopathology has been often depicted and frequently mirrors an overlap in diagnostic criteria as well [ $[15$, 25-27]. The inflammatory molecules and mediators involved in muscles affected by myositis are highly similar, given that some essential molecular paths engaged in immune response (innate and adaptive) are shared between the different IM subsets. The presence of autoantibodies, frequently detected in PM and DM, autoreactive lymphocytes, together with overexpression of major histocompatibility complex (MHC, or HLA, human leucocyte antigen) molecules on the surface of the affected myofibers albeit, at different degree, represent common traits of immune-mediated diseases. HLA molecules mediate the immune response by presenting processed antigen peptides, either self- or not-self, to activated T cells. In particular, $\mathrm{T}$ cells with Thl immune reaction predominance, macrophages, and dendritic cells (DC) are found in muscles of the different subgroups of IMs $[25,28]$. The presence of B lymphocytes, natural killer (NK) cells, or antigen presenting cell (APC) other than DC-such as endothelial or skeletal muscle cells themselves-have been also observed in all types of IMs [29-31]. However, albeit pathogenic mechanisms still are unclear, Th1 cells and macrophages play a pivotal role in IM pathogenesis: their local accumulation likely contributes to the deposition of immune complexes within skeletal muscles $[32,33]$ through the release of functional molecules, such as cytokines and chemokines; once present within the muscular microenvironment, they are able to cause damages directly to fibers and capillaries of the affected muscles [34]. The expression of cytokines as IFN $\gamma$, TNF $\alpha$, and several interleukins (IL), such as IL-6, IL-4, IL-17, or IL-12p40, is increased in muscle biopsies of IM subjects [35-38]. Interactions between cytokines/chemokines and lymphocytes, suggested to be the link between innate and adaptive immunity, are likely critical for IM type and stage [34]; in addition intrinsic mechanisms in skeletal muscle appear to be highly significant in IM pathogenesis as well.

\section{Skeletal Muscle as an Immunoactive Organ}

The immunocompetence of nonimmune tissues has been recognized as determinant to drive the course of immuneinflammatory processes in several diseases, from organ rejection to autoimmune pathologies $[39,40]$. Skeletal muscle cells are nowadays considered not only targets of immunological injury but actual active structures with intrinsic immunological capabilities [41-43].

3.1. Chemokines and Cytokines in Skeletal Muscle. Skeletal muscle is now considered as a secretory organ able to produce and release some cytokines-also termed myokines within the specific tissue context-to communicate with other organs, either in physiological conditions, that is, under contraction [42], or pathological conditions, as in inflammatory processes [43].

In particular, chemokines, a class of small cytokines with potent chemotactic activity, such as IL-8 (CXCL8), Mig (CXCL9), IP-10 (CXCL10), RANTES (CCL5), and MCP-1 (CCL2), are overexpressed during myositis in infiltrating inflammatory cells, extracellular matrix, and muscle fibers [32, 44-47]. Those molecules seem to have relevance for the immune pathogenesis of IMs because they promote and facilitate activated Th1 type cell trafficking to muscle tissues.

In line with this view, we have previously confirmed the importance of TNF $\alpha$ in IMs, suggesting new molecular insight(s) involving the important role of the chemokine CXCL10 in muscular inflammation $[48,49]$.

3.2. CXCL10 in Skeletal Muscle Inflammation. CXCL10 (or IP-10 $10 \mathrm{kD}$ IFN $\gamma$-induced protein) is a small peptide of CXC chemokine subfamily known to modulate innate and adaptive immune responses by controlling leukocyte trafficking $[40,50]$. It is secreted by several types of immune and resident cells under proinflammatory conditions [40]. It is known to polarize $\mathrm{T}$ cells towards Thl type dominance and seems to be directly associated to disease pathogenesis: through local tissue accumulation, it triggers and perpetuates a self-promoting inflammatory loop by interacting with its 
specific receptor CXCR3 on T, NK, B cells, macrophages, and DCs [40, 51-54]. Notably, human skeletal muscle cells challenged by inflammatory stimuli secrete significant amount of CXCL10 (virtually absent in basal condition), likely throughout a TNF $\alpha$-driven mechanism: $\mathrm{TNF} \alpha / \mathrm{TNF} \alpha$ receptor (TNF $\alpha \mathrm{R})$ system seems the critical one in promoting muscular inflammation at cellular level in human skeletal muscle cells, involving nuclear transcription factor $\kappa \mathrm{B}$ (NF$\kappa \mathrm{B})$, C-Jun NH2-terminal kinase (JNK), and extracellular signal-regulated kinase (ERK) intracellular path activation $[48,49]$. In particular, the specific blockage of NF- $\kappa B$ and JNK signaling significantly reduced CXCL10 secretion [49]. Thus, albeit CXCL10 is by definition an IFN $\gamma$-induced chemokine, it seems to be driven almost exclusively by TNF $\alpha$ in inflammatory processes within human skeletal muscle cells. That is, in our opinion, not so surprising.

3.3. The Route of TNF $\alpha$. TNF $\alpha$ is known as one of the essential cytokines in promoting muscular inflammation at cellular level $[55,56]$; it has been recently confirmed to be a key mediator involved in IM pathogenesis and, consequently, emerges as a potential therapeutic target [57-59]. Accordingly, the neutralization of TNF $\alpha$ activity with specific antibodies, TNF $\alpha$ R antagonists, or NF- $\kappa$ B inhibitors has been investigated in experimental animal models of myositis, in vitro and in vivo [60, 61]. Of notice, TNF $\alpha$ pharmacological blockade by the neutralizing antibody infliximab or the soluble $\mathrm{TNF} \alpha \mathrm{R}$ etanercept, already used in clinics for the treatment of rheumatoid arthritis or Crohn's disease, has been extended to IMs, although with some caution [62-65]. Thus far, as from our and other's studies, targeting TNF $\alpha, T N F \alpha$ R II-the subtype mainly engaged in immune response regulation $[48,66,67]$-and TNF $\alpha$-related pathways-directly associated with CXCL10 production by skeletal muscle cells [49] - might be beneficial for IM treatment.

Hence, the capability of some VDR agonists to target $\mathrm{TNF} \alpha$, as shown by different studies, seems quite intriguing, and we would like to point out VDR agonist skill to selectively impair TNF $\alpha$ signaling during inflammation processes in human skeletal muscle cells.

\section{VDR Agonists as Protolerogenic Molecules}

It is known that vitamin $\mathrm{D}$ plays a role in the control of immune cell function through VDR, with important effects onto the immune-mediated response toward protolerogenic dominance [68-72]. VDR agonists are able to attenuate excessive Th1-driven inflammation and avoid downstream Th1 polarization during inflammatory processes involved in allo- or autoimmune response, that is, in organ transplant rejection or autoimmune diseases, as recently addressed in a review on the topic [39].

Herein, we would like to underline that the protolerogenic activity of VDR relies on their capability to control maturation, differentiation, and activation of different type of immune cells, that is, monocytes, macrophages, $\mathrm{B}$ and $\mathrm{T}$ lymphocytes, neutrophils, and DC, throughout the activation of VDR, either constitutively present or induced in the majority of the immune cells $[73,74]$.
Since the pioneering studies by Bhalla et al. [75], VDR agonists have been documented to inhibit selectively Th1 cell development $[76,77]$ and directly Th1-type cytokines, such as IL-2 and IFN $\gamma$ [78-80]. In particular, while IL-2 inhibition is linked to an impairment of the transcription factor nuclear factor of activated T cells (NF-AT) complex formation, VDR ligand-induced IFN $\gamma$ negative regulation has been explained by a direct interaction of the ligandbound VDR complex with vitamin $\mathrm{D}$ responsive element (VDRE) within IFN $\gamma$ promoter [78-80]. However, some controversy arises against direct effects of VDR ligands onto IFN $\gamma$ inhibition [81]. Furthermore, T-cell activity can be inhibited by a VDR-mediated indirect mechanism through the downregulation of the expression of the MHC class II molecules and CD40, CD80, and CD86 costimulatory proteins in DC. DC are, indeed, well known targets of VDR ligands, which markedly impair IL-12-by targeting NF- $\kappa \mathrm{B}$, through Rel-B and c-Rel NF $\kappa$ B-related protein $[82,83]-$ and increase IL-10 production $[81,84-86]$. The prevention of DC differentiation and maturation, activation, and survival leads to DC protolerogenic phenotype and function along with T-cell hyporesponsiveness, as shown by in vivo and in vitro studies $[87,88]$. By the induction of protolerogenic DC phenotype, VDR ligands seem responsible for $\mathrm{CD} 4^{+} \mathrm{CD} 25^{+}$ regulatory T-cell enhancement $[89,90]$.

In addition, it is quite clear that VDR ligands directly target also Th17 cell subtype, as shown by the reduction of Th17 cytokines, such as IL-17A, IL-17F, and IL-22 by memory $\mathrm{T}$ cells in patients with early rheumatoid arthritis (RA) [91].

An enhanced development of Th2 type cells by VDR agonists throughout a direct effect on naive $\mathrm{CD} 4^{+}$cells has been reported [92]. A direct enhancement of Th2 type genes (i.e., IL-10, IL-4) is favored by VDR agonists while gene transcription of Th1/Th17 type cytokines (i.e., IL-2, IL-6, IL12 , IL-17, and IL-23) is declined $[93,94]$. Therefore, a definite switch of Th1 cell response towards Th2-mediated events occurs. Moreover, since macrophages [91, 95, 96], DC [97], and $\mathrm{T}$ cells [91] produce $1,25(\mathrm{OH})_{2} \mathrm{D}_{3}$, a contribution of this hormone to physiologically regulate innate and adaptive immunity could be speculated.

B cells, due to CYP27b1 (lalpha-hydroxylase) expression, have been hypothesized to be capable of autocrine/intracrine synthesis/response to vitamin D as well $[98,99]$. In particular, vitamin $\mathrm{D}$ seems to predominantly modulate human naïve $\mathrm{B}$ cells activation through the VDR target gene cyp24al and NF$\kappa \mathrm{B}[99]$ regulation.

So far, the anti-inflammatory feature of VDR agonists exerted onto several types of immune cells depends not only on VDR expression, but, and maybe especially, on the presence of common targets in their signal transduction pathways, such as the NF- $\kappa B$, downstream of TNF $\alpha[83,100]$. NF$\kappa \mathrm{B}$ is a key mediator of cytokine/chemokine-induced inflammation in several types of tissue resident cells and, notably a VDR agonist tissue target as well [48, 101-103] (Figure 1).

\section{VDR Agonists as Therapeutic Tools in IMs}

Based on the capacity to counteract NF-kB activation also in resident cells, VDR agonists cause a significant reduction 


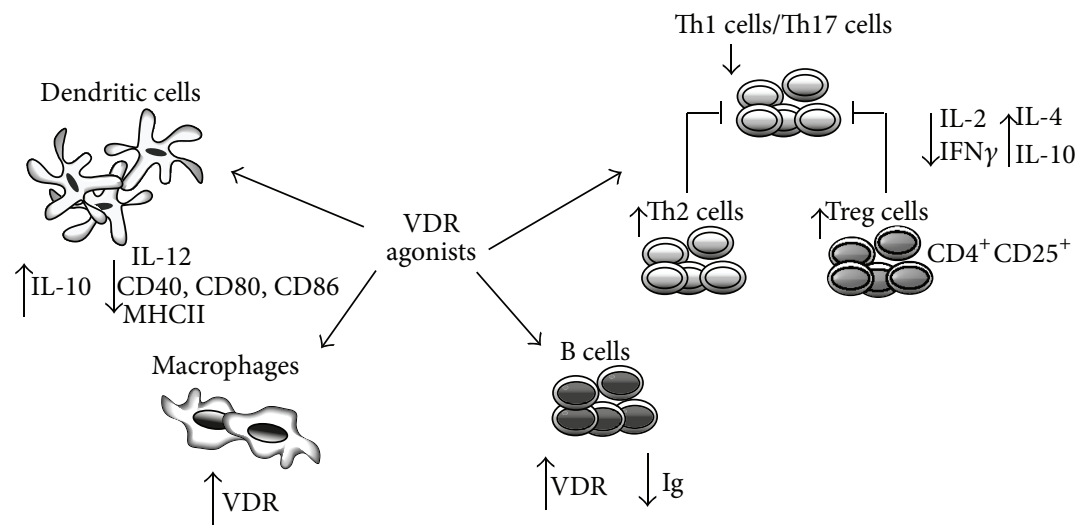

(a)

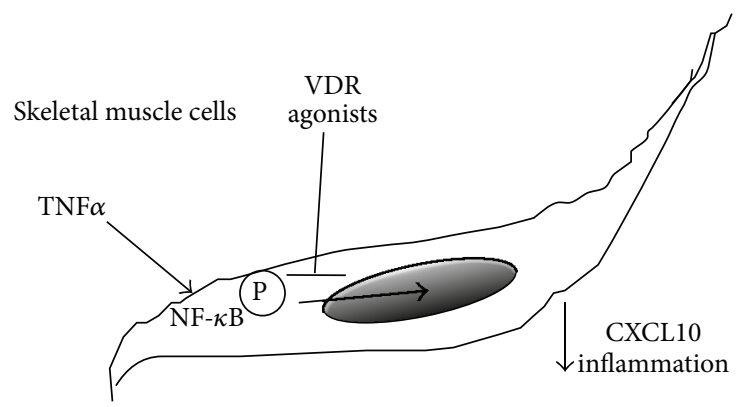

(b)

FIGURE 1: Schematic representation of protolerogenic effects of VDR ligands onto (a) immune cells, such as Th1/Th17, Th2, Treg subsets, DC, and macrophages and (b) skeletal muscle cells. Common targets, such as NF- $\kappa \mathrm{B}$, are involved to attenuate inflammation and promote a shift towards Th2 protolerogenic subtype dominance.

in local release of potent chemotactic factors-cytokines and chemokines-that, in turn, reduces the recruitment of immune cells (Th1 cells, macrophages, and DC) to the site of inflammation $[18,19,80,83]$. As a result, the mechanisms underlying the self-enhancing inflammatory loop between immune and resident cells are likely impaired. So far, the feature of VDR agonists to counteract the path downstream of $\mathrm{TNF} \alpha$ appears particularly relevant in view of a break up during inflammatory processes. Indeed, by interfering with NF- $\kappa \mathrm{B}$ nuclear translocation VDR agonists attenuate inflammation in several organ cell types such as adipocytes, thyrocytes, cardiomyocytes, in association to a decrease in proinflammatory cytokine production [20, 21, 104, 105].

We have recently reported on the effect of less-hypercalcemic VDR agonist BXL-01-0029 in human skeletal muscle cells under maximal inflammatory stimuli; it decreases CXCL10 secretion with the highest potency versus other current immunosuppressants and specifically deactivates TNF $\alpha$ pathways: JNK phosphorylation is reduced and, quite remarkably in our opinion, NF- $\kappa \mathrm{B}$ activation is prevented, while Statl activation, downstream of IFN $\gamma$, is unaffected. Hence, it appears that BXL-01-0029-induced inhibition of TNF $\alpha$ signal path may be sufficient to significantly decrease CXCL10 secretion by human skeletal muscle cells. This result seems quite intriguing considering the pivotal role of TNF $\alpha$ in muscular inflammation. Accordingly, in human skeletal muscle cells, differently from other cell types, such as human cardiomyocytes, thyrocytes, and renal cells, CXCL10 secretion seems to be essentially dependent on TNF $\alpha$-driven mechanisms.

As previously addressed, counteracting TNF $\alpha$ signal and, therefore, CXCL10 local accumulation might result in a relevant crumble in the self-enhancing inflammatory loop established between immune infiltrating cells and resident muscular cells. This effect appears even more significant when considering the limited efficacy of the current immunosuppressants in controlling inflammation in IMs.

An additional consequence of TNF $\alpha$ detrimental effects is a possible dysregulation of mitochondrial metabolic pathways occurring in inflammatory muscle diseases [106, 107]: abnormalities in energy regulating paths and deficiencies in glycolytic enzymes have been often observed in IM fibers with more pronounced damages [108, 109]. Even though those mechanisms have still to be fully clarified, myoblasts, immature myofibers, and proinflammatory cytokines, such as $\mathrm{TNF} \alpha$ and IL-15, seem the focal point for a cross talk between muscle inflammation and metabolism [34]. So far, targeting proinflammatory muscular cytokines secretion directly in myoblasts may be a quite helpful therapeutic strategy, considering the different possible beneficial effects.

The potential therapeutic application of BXL-01-0029 has been previously shown in nonobese diabetic (NOD) mice, who develop a pathogenesis similar to the human autoimmune type 1 diabetes (T1D), where VDR agonist-induced 
block of NF- $\kappa \mathrm{B}$ nuclear translocation in pancreatic islets is associated to a significant decrease both in Th1 cell organ infiltration and CXCL10 secretion [110]. We have also previously reported that BXL-01-0029 could be a potential steroidsparing agent in the current immunosuppressant cocktails used to control inflammation in heart or renal rejection after transplantation [21, 101]. Notably, BXL-01-0029 similarly to elocalcitol, another nonhypercalcemic VDR agonist, does not affect cell viability in several types of organ resident cells and in $\mathrm{CD}^{+}{ }^{+} \mathrm{T}$ cells, while significantly decreasing Th1- and Th17-cytokine secretion $[20,101]$. Conversely, the majority of immunosuppressants have been designed to reduce the number of immune cells; this specific effect accomplishes the appearance of the well known noxious side effects of immunosuppressive drugs, that is, from metabolic disturbances, to opportunistic infections or tumor development [13-15]. So far, VDR agonists are likely able to control immune reaction acting essentially onto the production of mediators of inflammation, cytokines, and chemokines.

It cannot be ignored that circulating cytokine level are related also to the disease stage, such as acute or chronic, reflecting Th1 or Th2 dominance; in this regard, and in line with a previous study in IM patients in active phase of the diseases [111], we have recently reported that, in sera of subjects at time of diagnosis with IMs CXCL10 is higher than in matched controls, and, importantly, is the highest as compared to some other circulating Thl cytokines-such as TNF $\alpha$, IFN $\gamma$, IL-8, IL-6, MCP-1, MIP-1 $\beta$ (Th1 type), and IL10 (Th2 type) [49]. Indeed, CXCL10, as Th1 type chemokine, participates to the early events in inflammatory/immune response and, even more important, is thought to trigger the reaction next to the antigenic challenge [54]. So far, we speculate that pharmacological targeting systemic and especially local muscular CXCL10 production with VDR agonists could result a particularly advantageous approach from the early stage of myositis.

\section{Remarks and Conclusion}

VDR agonists exert overall repressive effects onto Th1 polarized immune response, which dominates in inflammation, toward a more regulatory Th2 phenotype molecules, which dominate in tolerogenicity. Albeit the current controversy regarding VDR expression in adult skeletal muscle [112], as from our and other data, it appears that VDR agonists exert rapid anti-inflammatory effects directly in skeletal muscle cells. Whether VDR is expressed in skeletal muscle is still a debated issue $[1,112,113]$; the lower basal level in muscle as compared to duodenal cells-widely used as positive control-has been suggested as a possible cause of missing VDR detection in muscle cells [114]. Studies onto contractility and myogenesis showed that VDR is present and engaged in rapid nongenomic vitamin $\mathrm{D}$-induced activation of tyrosine phosphorylation cascade in muscle cells [115]. Several lines of evidence indicate a membrane-associated VDR as the mediator of vitamin $\mathrm{D}$-induced rapid events and, recently, the classical VDR located in caveolae has been shown to mediate vitamin D fast nongenomic signaling in skeletal muscle [114]. The existence of another cell surface receptor for vitamin D, named membrane associated, rapid response steroid binding (MARRS) has been reported in muscle [116].

Albeit the question on whether VDR exists in fully differentiated muscle or plays its pivotal role in myogenesis still is to be clarified, it is undeniable that vitamin D supplementation ameliorates proximal myopathy and muscle pain in patients with severe vitamin D deficiency $[2,117,118]$. Many reports on interventional studies are controversial; however vitamin $\mathrm{D}$ supplementation has been reported to improve musculoskeletal function in 12 weeks and reduce the risk of falls after 2 years in institutionalized subjects $[5,6,119]$. Based on their capability to balance immune system homeostasis, without being classical "immunosuppressants," and target local inflammatory mediators at muscular level, VDR ligands appear to be optimal candidates as novel therapeutic agents for IMs. Furthermore, additional benefits of VDR agonists are related to their protective effects against bone-loss, infective pathogens, neoplasies [120-122], all side effects of immunosuppressive agents. Nevertheless, the use of VDR agonists in clinics is generally not pursued and is limited to calcipotriol, a drug applied for psoriasis topic treatment [123].

In fact, despite many advantages, the limit in therapeutic applications of vitamin $\mathrm{D}$ and vitamin $\mathrm{D}$ analogues undeniably relies on the systemic toxicity often associated with long-term intake: hypercalcemia is the main risk associated to the supraphysiological doses of vitamin $\mathrm{D}$ necessary to reach the low local effective concentration $[124,125]$. Thus, the introduction of new molecules with immunosuppressive features without causing significant hypercalcemia has been strongly encouraged [126]. For this reason, drug development has been focusing on designing VDR agonists with a distinct separation between immunomodulatory and hypercalcemic potency. The selectivity is function of altered pharmacokinetics in comparison with the natural counterpart but, albeit quite many molecules eliciting much less calcemic effects have been developed, still discrepancies emerge between the therapeutic potential, as set in experimental work, and clinical data [127]. Those frustrating results may also depend on the lack of large and well designed trials.

Molecules with less or none hypercalcemic activity, as BXL-01-0029 or elocalcitol, could be suitable candidateseven as steroid-sparing agents-for inclusion in the therapeutic regimens for IMs. In particular, elocalcitol (150 $\mu \mathrm{g} /$ day P.O.) safety and tolerability in terms of calcemic effect has been proven in double-blind randomized study in 101 postmenopausal osteoporotic women, in placebo-controlled phase IIa (119 enrolled subjects) and follow-on phase IIb (514 patients) trial for the treatment of benign prostate hyperplasia (BPH) $[128,129]$. Further studies bridging basic, clinic, and pharmacological researches seem mandatory and local administration strategies could be envisioned for IM treatment to overcome systemic drug intake.

As previously stated, inadequate response to therapy and, consequently, poor outcome are often encountered by IM patients. The major concern in clinics is the absence of internationally validated evaluation criteria to conduct randomized controlled trials $[14,15]$ : in fact, the few validated assessment tools available provide limited information helpful to patient management. To overcome this limit, 
multidisciplinary consortiums, such as the International Myositis Assessment and Clinical Studies Group (IMACS, http://www.niehs.nih.gov/research/resources/imacs/), or Paediatric Rheumatology International Trials Organization (PRINTO, https://www.printo.it/)_including rheumatologists, neurologists, physiatrists dermatologists, and other myositis experts-have been established to develop consensus and standards for the conduct and reporting of myositis [14]. Albeit recent advances in understanding the pathogenesis of myositis are unquestionably important, adequate multicentre trials with validated outcome measures represent a must to be pursued in order to define the best treatment for IMs and give clinical remission as a realistic objective to IM patients.

\section{Conflict of Interests}

The author declares that there is no conflict of interests regarding the publication of this paper.

\section{References}

[1] C. M. Girgis, R. J. Clifton-Bligh, M. W. Hamrick, M. F. Holick, and J. E. Gunton, "The roles of vitamin D in skeletal muscle: form, function, and metabolism," Endocrine Review, vol. 34, pp. 33-83, 2013.

[2] L. Ceglia, "Vitamin D and its role in skeletal muscle," Current Opinion in Clinical Nutrition and Metabolic Care, vol. 12, no. 6, pp. 628-633, 2009.

[3] E. Giovannucci, "Expanding roles of vitamin D," The Journal of Clinical Endocrinology and Metabolism, vol. 94, no. 2, pp. 418420, 2009.

[4] M. Pfeifer, B. Begerow, H. W. Minne, K. Suppan, A. FahrleitnerPammer, and H. Dobnig, "Effects of a long-term vitamin D and calcium supplementation on falls and parameters of muscle function in community-dwelling older individuals," Osteoporosis International, vol. 20, no. 2, pp. 315-322, 2009.

[5] L. Flicker, R. J. MacInnis, M. S. Stein et al., "Should older people in residential care receive vitamin D to prevent falls? Results of a randomized trial," Journal of the American Geriatrics Society, vol. 53, no. 11, pp. 1881-1888, 2005.

[6] H. A. Bischoff-Ferrari, B. Dawson-Hughes, W. C. Willett et al., "Effect of vitamin D on falls: a meta-analysis," The Journal of the American Medical Association, vol. 291, no. 16, pp. 1999-2006, 2004.

[7] T. H. J. Burne, J. J. McGrath, D. W. Eyles, and A. Mackay-Sim, "Behavioural characterization of vitamin D receptor knockout mice," Behavioural Brain Research, vol. 157, no. 2, pp. 299-308, 2005.

[8] I. Endo, D. Inoue, T. Mitsui et al., "Deletion of vitamin D receptor gene in mice results in abnormal skeletal muscle development with deregulated expression of myoregulatory transcription factors," Endocrinology, vol. 144, no. 12, pp. 5138-5144, 2003.

[9] Y. C. Li, A. E. Pirro, M. Amling et al., "Targeted ablation of the vitamin D receptor: an animal model of vitamin Ddependent rickets type II with alopecia," Proceedings of the National Academy of Sciences of the United States of America, vol. 94, no. 18, pp. 9831-9835, 1997.

[10] A. Windelinckx, G. de Mars, G. Beunen et al., "Polymorphisms in the vitamin $\mathrm{D}$ receptor gene are associated with muscle strength in men and women," Osteoporosis International, vol. 18, no. 9, pp. 1235-1242, 2007.

[11] C. M. Girgis, R. J. Clifton-Bligh, N. Mokbel, K. Cheng, and J. E. Gunton, "Vitamin D signaling regulates proliferation, differentiation and myotube size in C2C12 skeletal muscle cells," Endocrinology, vol. 155, pp. 347-357, 2014.

[12] J. W. Prineas, A. S. Mason, and R. A. Henson, "Myopathy in metabolic bone disease," British Medical Journal, vol. 1, pp. 10341036, 1965.

[13] M. C. Dalakas, "Immunotherapy of myositis: issues, concerns and future prospects," Nature Reviews Rheumatology, vol. 6, no. 3, pp. 129-137, 2010.

[14] F. W. Miller, "New approaches to the assessment and treatment of the idiopathic inflammatory myopathies," Annals of the Rheumatic Diseases, vol. 71, no. 2, pp. i82-i85, 2012.

[15] F. C. Ernste and A. M. Reed, "Idiopathic inflammatory myopathies: current trends in pathogenesis, clinical features, and up-to-date treatment recommendations," Mayo Clinical Proceeding, vol. 88, pp. 83-105, 2013.

[16] B. Hamilton, "Vitamin D and human skeletal muscle," Scandinavian Journal of Medicine and Science in Sports, vol. 20, no. 2, pp. 182-190, 2010.

[17] R. Bouillon, H. Bischoff-Ferrari, and W. Willett, "Vitamin D and health: perspectives from mice and man," Journal of Bone and Mineral Research, vol. 23, no. 7, pp. 974-979, 2008.

[18] C. J. Glueck and B. Conrad, "Severe vitamin D deficiency, myopathy and rhabdomyolysis," North American Journal of Medical Sciences, vol. 5, pp. 494-495, 2013.

[19] Y. Arnson, H. Amital, and Y. Shoenfeld, "Vitamin D and autoimmunity: new aetiological and therapeutic considerations," Annals of the Rheumatic Diseases, vol. 66, no. 9, pp. 11371142, 2007.

[20] E. Borgogni, E. Sarchielli, M. Sottili et al., "Elocalcitol inhibits inflammatory responses in human thyroid cells and T cells," Endocrinology, vol. 149, no. 7, pp. 3626-3634, 2008.

[21] M. Sottili, L. Cosmi, E. Borgogni et al., "Immunomodulatory effects of BXL-01-0029, a less hypercalcemic vitamin D analogue, in human cardiomyocytes and T cells," Experimental Cell Research, vol. 315, no. 2, pp. 264-273, 2009.

[22] M. C. Dalakas, "Medical progress: polymyositis, dermatomyositis, and inclusion-body myositis," The New England Journal of Medicine, vol. 325, no. 21, pp. 1487-1498, 1991.

[23] M. C. Dalakas, "Pathophysiology of inflammatory and autoimmune myopathies," Presse Medicale, vol. 40, no. 4, pp. e237-e247, 2011.

[24] R. Mantegazza, P. Bernasconi, P. Confalonieri, and F. Cornelio, "Inflammatory myopathies and systemic disorders: a review of immunopathogenetic mechanisms and clinical features," Journal of Neurology, vol. 244, no. 5, pp. 277-287, 1997.

[25] C. Grundtman, V. Malmström, and I. E. Lundberg, "Immune mechanisms in the pathogenesis of idiopathic inflammatory myopathies," Arthritis Research and Therapy, vol. 9, no. 2, article 208, 2007.

[26] K. Arahata and A. G. Engel, "Monoclonal antibody analysis of mononuclear cells in myopathies. I: quantitation of subsets according to diagnosis and sites of accumulation and demonstration and counts of muscle fibers invaded by T cells," Annals of Neurology, vol. 16, no. 2, pp. 193-208, 1984.

[27] A. G. Engel, K. Arahata, and A. Emslie-Smith, "Immune effector mechanisms in inflammatory myopathies," Research Publications-Association for Research in Nervous and Mental Disease, vol. 68, pp. 141-157, 1990. 
[28] B. de Paepe, K. K. Creus, and J. L. de Bleecker, "Role of cytokines and chemokines in idiopathic inflammatory myopathies," Current Opinion in Rheumatology, vol. 21, no. 6, pp. 610-616, 2009.

[29] K. Nagaraju, "Update on immunopathogenesis in inflammatory myopathies," Current Opinion in Rheumatology, vol. 13, no. 6, pp. 461-468, 2001.

[30] J.-H. Choi, Y.-E. Park, S.-I. Kim et al., "Differential Immunohistological features of inflammatory myopathies and dysferlinopathy," Journal of Korean Medical Science, vol. 24, no. 6, pp. 1015-1023, 2009.

[31] A. Tournadre and P. Miossec, "Chemokines and dendritic cells in inflammatory myopathies," Annals of the Rheumatic Diseases, vol. 68, no. 3, pp. 300-304, 2009.

[32] M. C. Dalakas and R. Hohlfeld, "Polymyositis and dermatomyositis," The Lancet, vol. 362, no. 9388, pp. 971-982, 2003.

[33] R. Hohlfeld, A. G. Engel, N. Goebels, and L. Behrens, "Cellular immune mechanisms in inflammatory myopathies," Current Opinion in Rheumatology, vol. 9, no. 6, pp. 520-526, 1997.

[34] S. Rayavarapu, W. Coley, T. B. Kinder, and K. Nagaraju, "Idiopathic inflammatory myopathies: pathogenic mechanisms of muscle weakness," Skeletal Muscle, vol. 3, article 13, 2013.

[35] A. Brunn, K. Zornbach, V. H. Hans, W. F. Haupt, and M. Deckert, "Toll-like receptors promote inflammation in idiopathic inflammatory myopathies," Journal of Neuropathology and Experimental Neurology, vol. 3, pp. 855-867, 2012.

[36] I. Lundberg, J. M. Brengman, and A. G. Engel, "Analysis of cytokine expression in muscle in inflammatory myopathies, Duchenne dystrophy, and non-weak controls," Journal of Neuroimmunology, vol. 63, no. 1, pp. 9-16, 1995.

[37] B. de Paepe, K. K. Creus, and J. L. de Bleecker, "Chemokines in idiopathic inflammatory myopathies," Frontiers in Bioscience, vol. 13, no. 7, pp. 2548-2577, 2008.

[38] D. S. Tews and H. H. Goebel Cytokine, "Expression profile in idiopathic inflammatory myopathies," Journal of Neuropathology \& Experimental Neurology, vol. 55, pp. 342-347, 1996.

[39] S. Scolletta, M. Colletti, L. di Luigi, and C. Crescioli, "Vitamin D receptor agonists target CXCL10: new therapeutic tools for resolution of inflammation," Mediators of Inflammation, vol. 2013, Article ID 876319, 11 pages, 2013.

[40] P. Romagnani and C. Crescioli, "CXCL10: a candidate biomarker in transplantation," Clinica Chimica Acta, vol. 413, pp. 1364-1373, 2012.

[41] K. Nagaraju, N. Raben, G. Merritt, L. Loeffler, K. Kirk, and P. Plotz, "A variety of cytokines and immunologically relevant surface molecules are expressed by normal human skeletal muscle cells under proinflammatory stimuli," Clinical and Experimental Immunology, vol. 113, no. 3, pp. 407-414, 1998.

[42] B. K. Pedersen, "Edward F. Adolph Distinguished Lecture: muscle as an endocrine organ: IL-6 and other myokines," The Journal of Applied Physiology, vol. 107, no. 4, pp. 1006-1014, 2009.

[43] I. Loell and I. E. Lundberg, "Can muscle regeneration fail in chronic inflammation: a weakness in inflammatory myopathies?" Journal of Internal Medicine, vol. 269, no. 3, pp. 243257, 2011.

[44] M. E. DeVries, K. A. Hosiawa, C. M. Cameron et al., "The role of chemokines and chemokine receptors in alloantigen-independent and alloantigen-dependent transplantation injury," Seminars in Immunology, vol. 15, no. 1, pp. 33-48, 2003.

[45] M. de Rossi, P. Bernasconi, F. Baggi, R. de Waal Malefyt, and R. Mantegazza, "Cytokines and chemokines are both expressed by human myoblasts: possible relevance for the immune pathogenesis of muscle inflammation," International Immunology, vol. 12, no. 9, pp. 1329-1335, 2000.

[46] R. Raju, O. M. Vasconcelos, C. Semino-Mora, R. P. Granger, and M. C. Dalakas, "Expression of interferon-gamma inducible chemokines in the muscles of patients with inclusion body myositis," Neurology, vol. 58, p. A390, 2002.

[47] P. Confalonieri, P. Bernasconi, P. Megna, S. Galbiati, F. Cornelio, and R. Mantegazza, "Increased expression of $\beta$-chemokines in muscle of patients with inflammatory myopathies," Journal of Neuropathology and Experimental Neurology, vol. 59, no. 2, pp. $164-169,2000$.

[48] C. Crescioli, M. Sottili, P. Bonini et al., "Inflammatory response in human skeletal muscle cells: CXCL10 as a potential therapeutic target," European Journal of Cell Biology, vol. 91, no. 2, pp. 139-149, 2012.

[49] L. di Luigi, M. Sottili, C. Antinozzi et al., "The vitamin D receptor agonist BXL-01-0029 as a potential new pharmacological tool for the treatment of inflammatory myopathies," PLOS ONE, vol. 8, Article ID e77745, 2013.

[50] A. D. Luster and J. V. Ravetch, "Biochemical characterization of a $\gamma$ interferon-inducible cytokine (IP-10)," Journal of Experimental Medicine, vol. 166, no. 4, pp. 1084-1097, 1987.

[51] M. Loetscher, B. Gerber, P. Loetscher et al., "Chemokine receptor specific for IP10 and Mig: structure, function, and expression in activate T-Lymphocytes," Journal of Experimental Medicine, vol. 184, no. 3, pp. 963-969, 1996.

[52] M. Loetscher, P. Moetscher, N. Brass, E. Meese, and B. Moser, "Lymphocyte-specific chemokine receptor CXCR3: regulation, chemokine binding and gene localization," European Journal of Immunology, vol. 28, pp. 3696-3705, 1998.

[53] S. Qin, J. B. Rottman, P. Myers et al., “The chemokine receptors CXCR3 and CCR5 mark subsets of T cells associated with certain inflammatory reactions," The Journal of Clinical Investigation, vol. 101, no. 4, pp. 746-754, 1998.

[54] J. D. Campbell, V. Gangur, F. E. R. Simons, and K. T. HayGlass, "Allergic humans are hyporesponsive to a CXCR3 ligandmediated Thl immunity-promoting loop," The FASEB Journal, vol. 18, no. 2, pp. 329-331, 2004.

[55] D. Figarella-Branger, M. Civatte, C. Bartoli, and J.-F. Pellissier, "Cytokines, chemokines, and cell adhesion molecules in inflammatory myopathies," Muscle and Nerve, vol. 28, no. 6, pp. 659682, 2003.

[56] L. Frasca, M. Nasso, F. Spensieri et al., "IFN- $\gamma$ arms human dendritic cells to perform multiple effector functions," Journal of Immunology, vol. 180, no. 3, pp. 1471-1481, 2008.

[57] S. Forsgren, L. Renström, C. Purdam, and J. E. Gaida, “TNFalpha in the locomotor system beyond joints: high degree of involvement in myositis in a rabbit model," International Journal of Rheumatology, vol. 2012, Article ID 637452, 11 pages, 2012.

[58] H. Chinoy, F. Salway, S. John et al., "Tumour necrosis factor- $\alpha$ single nucleotide polymorphisms are not independent of HLA class I in UK Caucasians with adult onset idiopathic inflammatory myopathies," Rheumatology, vol. 46, no. 9, pp. 1411-1416, 2007.

[59] C. W. Keller, C. Fokken, S. G. Turville et al., “TNF- $\alpha$ induces macroautophagy and regulates MHC class II expression in human skeletal muscle cells," The Journal of Biological Chemistry, vol. 286, no. 5, pp. 3970-3980, 2011. 
[60] A. R. Baudy, N. Saxena, H. Gordish, E. P. Hoffman, and K. Nagaraju, "A robust in vitro screening assay to identify NF$\kappa \mathrm{B}$ inhibitors for inflammatory muscle diseases," International Immunopharmacology, vol. 9, no. 10, pp. 1209-1214, 2009.

[61] T. Sugihara, N. Okiyama, N. Watanabe, N. Miyasaka, and H. Kohsaka, "Interleukin-1 and tumor necrosis factor $\alpha$ blockade treatment of experimental polymyositis in mice," Arthritis and Reumatism, vol. 64, pp. 2655-2662, 2012.

[62] A. Tournadre, J.-J. Dubost, and M. Soubrier, "Treatment of inflammatory muscle disease in adults," Joint Bone Spine, vol. 77, no. 5, pp. 390-394, 2010.

[63] S. Hodgetts, H. Radley, M. Davies, and M. D. Grounds, "Reduced necrosis of dystrophic muscle by depletion of host neutrophils, or blocking TNF $\alpha$ function with Etanercept in $\mathrm{mdx}$ mice," Neuromuscular Disorders, vol. 16, no. 9-10, pp. 591-602, 2006.

[64] P. Efthimiou, "Tumor necrosis factor- $\alpha$ in inflammatory myopathies: pathophysiology and therapeutic implications," Seminars in Arthritis and Rheumatism, vol. 36, no. 3, pp. 168-172, 2006.

[65] S. Dold, M. E. Justiniano, J. Marquez, and L. R. Espinoza, "Treatment of early and refractory dermatomyositis with infliximab: a report of two cases," Clinical Rheumatology, vol. 26, no. 7, pp. 1186-1188, 2007.

[66] T. Hehlgans and K. Pfeffer, "The intriguing biology of the tumour necrosis factor/tumour necrosis factor receptor superfamily: players, rules and the games," Immunology, vol. 115, no. 1, pp. 1-20, 2005.

[67] G. C. Suvannavejh, H.-O. Lee, J. Padilla, M. C. Dal Canto, T. A. Barrett, and S. D. Miller, "Divergent roles for p55 and p75 tumor necrosis factor receptors in the pathogenesis of $\mathrm{MOG}_{35-55^{-}}$ induced experimental autoimmune encephalomyelitis," Cellular Immunology, vol. 205, no. 1, pp. 24-33, 2000.

[68] Y. Abu-Amer and Z. Bar-Shavit, "Impaired bone marrowderived macrophage differentiation in vitamin D deficiency," Cellular Immunology, vol. 151, no. 2, pp. 356-368, 1993.

[69] H. P. Koeffler, H. Reichel, J. E. Bishop, and A. W. Norman, “ $\gamma$ interferon stimulates production of 1,25-dihydroxyvitamin $\mathrm{D}_{3}$ by normal human macrophages," Biochemical and Biophysical Research Communications, vol. 127, no. 2, pp. 596-603, 1985.

[70] H. Reichel, H. P. Koeffler, J. E. Bishop, and A. W. Norman, "25-hydroxyvitamin $\mathrm{D}_{3}$ metabolism by lipopolysaccharidestimulated normal human macrophages," The Journal of Clinical Endocrinology and Metabolism, vol. 64, no. 1, pp. 1-9, 1987.

[71] L. J. Dickie, L. D. Church, L. R. Coulthard, R. J. Mathews, P. Emery, and M. F. McDermott, "Vitamin $\mathrm{D}_{3}$ down-regulates intracellular Toll-like receptor 9 expression and Toll-like receptor 9-induced IL-6 production in human monocytes," Rheumatology, vol. 49, no. 8, pp. 1466-1471, 2010.

[72] K. Sadeghi, B. Wessner, U. Laggner et al., "Vitamin $\mathrm{D}_{3}$ downregulates monocyte TLR expression and triggers hyporesponsiveness to pathogen-associated molecular patterns," European Journal of Immunology, vol. 36, no. 2, pp. 361-370, 2006.

[73] D. M. Provvedini, C. D. Tsoukas, L. J. Deftos, and S. C. Manolagas, "1,25-dihydroxyvitamin $\mathrm{D}_{3}$ receptors in human leukocytes," Science, vol. 221, no. 4616, pp. 1181-1183, 1983.

[74] F. Baeke, H. Korf, L. Overbergh et al., "Human T lymphocytes are direct targets of 1,25-dihydroxyvitamin $\mathrm{D}_{3}$ in the immune system," The Journal of Steroid Biochemistry and Molecular Biology, vol. 121, no. 1-2, pp. 221-227, 2010.

[75] A. K. Bhalla, E. P. Amento, B. Serog, and L. H. Glimcher, "1,25-dihydroxyvitamin $\mathrm{D}_{3}$ inhibits antigen-induced $\mathrm{T}$ cell activation," Journal of Immunology, vol. 133, no. 4, pp. 1748-1754, 1984.

[76] J. M. Lemire, D. C. Archer, L. Beck, and H. L. Spiegelberg, "Immunosuppressive actions of 1,25-dihydroxyvitamin $\mathrm{D}_{3}$ : preferential inhibition of Th1 functions," The Journal of Nutrition, vol. 125, no. 6, pp. 1704S-1708S, 1995.

[77] F. Matter, S. Smiroldo, F. Galbiati et al., "Inhibition of Th1 development and treatment of chronic-relapsing experimental allergic encephalomyelitis by a non-hypercalcemic analogue of 1, 25-dihydroxyvitamin $\mathrm{D}_{3}$," European Journal of Immunology, vol. 30, pp. 498-508, 2000.

[78] I. Alroy, T. L. Towers, and L. P. Freedman, "Transcriptional repression of the interleukin-2 gene by vitamin $\mathrm{D}_{3}$ : direct inhibition of NFATp/AP-1 complex formation by a nuclear hormone receptor," Molecular and Cellular Biology, vol. 15, no. 10, pp. 5789-5799, 1995.

[79] A. Takeuchi, G. S. Reddy, T. Kobayashi, T. Okano, J. Park, and S. Sharma, "Nuclear factor of activated T cells (NFAT) as a molecular target for $1 \alpha, 25$-dihydroxyvitamin $\mathrm{D}_{3}$-mediated effects," Journal of Immunology, vol. 160, no. 1, pp. 209-218, 1998.

[80] M. Cippitelli and A. Santoni, "Vitamin $\mathrm{D}_{3}$ : a transcriptional modulator of the interferon-gamma gene," European Journal of Immunology, vol. 28, pp. 3017-3030, 1998.

[81] M. T. Cantorna, W. D. Woodward, C. E. Hayes, and H. F. DeLuca, "1,25-dihydroxyvitamin $\mathrm{D}_{3}$ is a positive regulator for the two anti- encephalitogenic cytokines TGF- $\beta 1$ and IL-4," Journal of Immunology, vol. 160, no. 11, pp. 5314-5319, 1998.

[82] M. D. Griffin, N. Xing, and R. Kumar, "Vitamin D and its analogs as regulators of immune activation and antigen presentation," Annual Review of Nutrition, vol. 23, pp. 117-145, 2003.

[83] Q. Li and I. M. Verma, "NF- $\kappa$ B regulation in the immune system," Nature Reviews Immunology, vol. 2, no. 10, pp. 725-734, 2002.

[84] E. Hyppönen, E. Läärä, A. Reunanen, M.-R. Järvelin, and S. $\mathrm{M}$. Virtanen, "Intake of vitamin $\mathrm{D}$ and risk of type 1 diabetes: a birth-cohort study," The Lancet, vol. 358, no. 9292, pp. 1500$1503,2001$.

[85] D. D. Branisteanu, M. Waer, H. Sobis, S. Marcelis, M. Vandeputte, and R. Bouillon, "Prevention of murine experimental allergic encephalomyelitis: cooperative effects of cyclosporine and $1 \alpha, 25-(\mathrm{OH})_{2} \mathrm{D}_{3}$," Journal of Neuroimmunology, vol. 61, no. 2, pp. 151-160, 1995.

[86] M. K. Racke, S. Dhib-Jalbut, B. Cannella, P. S. Albert, C. S. Raine, and D. E. McFarlin, "Prevention and treatment of chronic relapsing experimental allergic encephalomyelitis by transforming growth factor- $\beta 1$," Journal of Immunology, vol. 146, no. 9, pp. 3012-3017, 1991.

[87] S. Gregori, M. Casorati, S. Amuchastegui, S. Smiroldo, A. M. Davalli, and L. Adorini, "Regulatory T cells induced by $1 \alpha, 25$ dihydroxyvitamin $\mathrm{D}_{3}$ and mycophenolate mofetil treatment mediate transplantation tolerance," Journal of Immunology, vol. 167, no. 4, pp. 1945-1953, 2001.

[88] M. D. Griffin, W. Lutz, V. A. Phan, L. A. Bachman, D. J. McKean, and R. Kumar, "Dendritic cell modulation by $1 \alpha, 25$ dihydroxyvitamin $\mathrm{D}_{3}$ and its analogs: a vitamin $\mathrm{D}$ receptor-dependent pathway that promotes a persistent state of immaturity in vitro and in vivo," Proceedings of the National Academy of Sciences of the United States of America, vol. 98, no. 12, pp. 6800-6805, 2001.

[89] J. Wang, M. Nuite, and T. E. McAlindon, "Association of estrogen and aromatase gene polymorphisms with systemic lupus erythematosus," Lupus, vol. 19, no. 6, pp. 734-740, 2010. 
[90] J.-C. Souberbielle, J.-J. Body, J. M. Lappe et al., "Vitamin D and musculoskeletal health, cardiovascular disease, autoimmunity and cancer: recommendations for clinical practice," Autoimmunity Reviews, vol. 9, no. 11, pp. 709-715, 2010.

[91] E. M. Colin, P. S. Asmawidjaja, J. P. van Hamburg et al., "1,25-dihydroxyvitamin $\mathrm{D}_{3}$ modulates Th17 polarization and interleukin-22 expression by memory $\mathrm{T}$ cells from patients with early rheumatoid arthritis," Arthritis and Rheumatism, vol. 62, no. 1, pp. 132-142, 2010.

[92] A. Boonstra, F. J. Barrat, C. Crain, V. L. Heath, H. F. J. Savelkoul, and A. O'Garra, " $1 \alpha, 25$-dihydroxyvitamin $\mathrm{D}_{3}$ has a direct effect on naïve $\mathrm{CD} 4{ }^{+} \mathrm{T}$ cells to enhance the development of Th2 cells," Journal of Immunology, vol. 167, no. 9, pp. 4974-4980, 2001.

[93] E. van Etten and C. Mathieu, "Immunoregulation by 1,25dihydroxyvitamin $\mathrm{D}_{3}$ : basic concepts," The Journal of Steroid Biochemistry and Molecular Biology, vol. 97, no. 1-2, pp. 93-101, 2005.

[94] A. W. Pedersen, K. Holmstrøm, S. S. Jensen et al., "Phenotypic and functional markers for $1 \alpha, 25$-dihydroxyvitamin $\mathrm{D}_{3}$ modified regulatory dendritic cells," Clinical and Experimental Immunology, vol. 157, no. 1, pp. 48-59, 2009.

[95] S. Joshi, L.-C. Pantalena, X. K. Liu et al., "1,25-dihydroxyvitamin $\mathrm{D}_{3}$ ameliorates Th17 autoimmunity via transcriptional modulation of interleukin-17A," Molecular and Cellular Biology, vol. 31, no. 17, pp. 3653-3669, 2011.

[96] A.-L. Khoo, L. Y. A. Chai, H. J. P. M. Koenen et al., "Regulation of cytokine responses by seasonality of vitamin D status in healthy individuals," Clinical and Experimental Immunology, vol. 164, no. 1, pp. 72-79, 2011.

[97] J. Fritsche, K. Mondal, A. Ehrnsperger, R. Andreesen, and M. Kreutz, "Regulation of 25-hydroxyvitamin D3-1 alpha-hydroxylase and production of 1 alpha,25-dihydroxyvitamin D3 by human dendritic cells," Blood, vol. 102, no. 9, pp. 3314-3316, 2003.

[98] S. Chen, G. P. Sims, X. X. Chen, Y. Y. Gu, S. Chen, and P. E. Lipsky, "Modulatory effects of 1,25-dihydroxyvitamin $\mathrm{D}_{3}$ on human B cell differentiation," Journal of Immunology, vol. 179, no. 3, pp. 1634-1647, 2007.

[99] K. Geldmeyer-Hilt, G. Heine, B. Hartmann, R. Baumgrass, A. Radbruch, and $M$. Worm, "1,25-dihydroxyvitamin $\mathrm{D}_{3}$ impairs NF- $\kappa \mathrm{B}$ activation in human naive B cells," Biochemical and Biophysical Research Communications, vol. 407, no. 4, pp. 699702, 2011.

[100] L. Adorini, "Intervention in autoimmunity: the potential of vitamin D receptor agonists," Cellular Immunology, vol. 233, no. 2, pp. 115-124, 2005.

[101] C. Sagrinati, M. Sottili, B. Mazzinghi et al., "Comparison between VDR analogs and current immunosuppressive drugs in relation to CXCL10 secretion by human renal tubular cells," Transplant International, vol. 23, no. 9, pp. 914-923, 2010.

[102] C. Crescioli, L. Cosmi, E. Borgogni et al., "Methimazole inhibits CXC chemokine ligand 10 secretion in human thyrocytes," Journal of Endocrinology, vol. 195, no. 1, pp. 145-155, 2007.

[103] C. Crescioli, R. Squecco, L. Cosmi et al., "Immunosuppression in cardiac graft rejection: a human in vitro model to study the potential use of new immunomodulatory drugs," Experimental Cell Research, vol. 314, no. 6, pp. 1337-1350, 2008.

[104] S. J. Mutt, T. Karhu, S. Lehtonen et al., "Inhibition of cytokine secretion from adipocytes by 1,25 -dihydroxyvitamin $\mathrm{D}_{3}$ via the NF- $\kappa$ B pathway," The FASEB Journal, vol. 26, no. 11, pp. 44004407, 2012.
[105] Y. Chen, J. Kong, T. Sun et al., "1,25-dihydroxyvitamin $\mathrm{D}_{3}$ suppresses inflammation-induced expression of plasminogen activator inhibitor-1 by blocking nuclear factor- $\kappa \mathrm{B}$ activation," Archives of Biochemistry and Biophysics, vol. 507, no. 2, pp. 241247, 2011.

[106] P. Temiz, C. C. Weihl, and A. Pestronk, "Inflammatory myopathies with mitochondrial pathology and protein aggregates," Journal of the Neurological Sciences, vol. 278, no. 1-2, pp. 25-29, 2009.

[107] J. M. Schröder and M. Molnar, "Mitochondrial abnormalities and peripheral neuropathy in inflammatory myopathy, especially inclusion body myositis," Molecular and Cellular Biochemistry, vol. 174, no. 1-2, pp. 277-281, 1997.

[108] Ó. Miró, J. Casademont, J. M. Grau, D. Jarreta, Á. UrbanoMárquez, and F. Cardellach, "Histological and biochemical assessment of mitochondrial function in dermatomyositis," British Journal of Rheumatology, vol. 37, no. 10, pp. 1047-1053, 1998.

[109] M. I. Alhatou, J. T. Sladky, O. Bagasra, and J. D. Glass, "Mitochondrial abnormalities in dermatomyositis: characteristic pattern of neuropathology," Journal of Molecular Histology, vol. 35, no. 6, pp. 615-619, 2004.

[110] S. Gregori, N. Giarratana, S. Smiroldo, M. Uskokovic, and L. Adorini, "A $1 \alpha, 25$-dihydroxyvitamin $\mathrm{D}_{3}$ analog enhances regulatory T-cells and arrests autoimmune diabetes in NOD mice," Diabetes, vol. 51, no. 5, pp. 1367-1374, 2002.

[111] P. Szodoray, P. Alex, N. Knowlton et al., "Idiopathic inflammatory myopathies, signified by distinctive peripheral cytokines, chemokines and the TNF family members B-cell activating factor and a proliferation inducing ligand," Rheumatology, vol. 49, no. 10, pp. 1867-1877, 2010.

[112] Y. Wang and H. F. DeLuca, "Is the vitamin D receptor found in muscle?” Endocrinology, vol. 152, no. 2, pp. 354-363, 2011.

[113] H. A. Bischoff, M. Borchers, F. Gudat et al., "In situ detection of 1,25-dihydroxyvitamin $\mathrm{D}_{3}$ receptor in human skeletal muscle tissue," Histochemical Journal, vol. 33, no. 1, pp. 19-24, 2001.

[114] C. Buitrago, V. Gonzalez Pardo, and R. Boland, "Role of VDR in $1 \alpha, 25$-dihydroxyvitamin $\mathrm{D}_{3}$-dependent non-genomic activation of MAPKs, Src and Akt in skeletal muscle cells," Journal of Steroid Biochemistry \& Molecular Biology, vol. 136, pp. 125-130, 2013.

[115] R. L. Boland, "VDR activation of intracellular signaling pathways in skeletal muscle," Molecular and Cellular Endocrinology, vol. 347, no. 1-2, pp. 11-16, 2011.

[116] R. C. Khanal and I. Nemere, “The ERp57/GRp58/1,25D - $^{-}$ MARRS receptor: multiple functional roles in diverse cell systems," Current Medicinal Chemistry, vol. 14, no. 10, pp. 10871093, 2007.

[117] R. J. Menaker, P. J. M. Ceponis, and N. L. Jones, "Helicobacter pylori induces apoptosis of macrophages in association with alterations in the mitochondrial pathway," Infection and Immunity, vol. 72, no. 5, pp. 2889-2898, 2004.

[118] S. E. Mercer, D. Z. Ewton, X. Deng, S. Lim, T. R. Mazur, and E. Friedman, "Mirk/Dyrk1B mediates survival during the differentiation of $\mathrm{C} 2 \mathrm{C} 12$ myoblasts," The Journal of Biological Chemistry, vol. 280, no. 27, pp. 25788-25801, 2005.

[119] C. M. Girgis, R. J. Clifton-Bligh, N. Turner, S. L. Lau, and J. E. Gunton, "Effects of vitamin D in skeletal muscle: falls, strength, athletic performance and insulin sensitivity," Clinical Endocrinology, vol. 80, pp. 169-181, 2014. 
[120] H.-U. Stempfle, C. Werner, U. Siebert et al., "The role of tacrolimus (FK506)-based immunosuppression on bone mineral density and bone turnover after cardiac transplantation: a prospective, longitudinal, randomized, double-blind trial with calcitriol," Transplantation, vol. 73, no. 4, pp. 547-552, 2002.

[121] M. T. Cantorna, D. A. Hullett, C. Redaelli et al., "1,25-dihydroxyvitamin $\mathrm{D}_{3}$ prolongs graft survival without compromising host resistance to infection or bone mineral density," Transplantation, vol. 66, no. 7, pp. 828-831, 1998.

[122] G. Picotto, A. C. Liaudat, L. Bohl, and N. T. Talamoni, "Molecular aspects of vitamin D anticancer activity," Cancer Investigation, vol. 30, pp. 604-614, 2012.

[123] L. J. Scott, C. J. Dunn, and K. L. Goa, "Calcipotriol ointment: a review of its use in the management of psoriasis," American Journal of Clinical Dermatology, vol. 2, no. 2, pp. 95-120, 2001.

[124] M. di Rosa, M. Malaguarnera, F. Nicoletti, and L. Malaguarnera, "Vitamin $\mathrm{D}_{3}$ : a helpful immuno-modulator," Immunology, vol. 134, no. 2, pp. 123-139, 2011.

[125] D. B. Endres, "Investigation of hypercalcemia," Clinical Biochemistry, vol. 45, pp. 954-963, 2012.

[126] T. Takahashi and K. Morikawa, "Vitamin D receptor agonists: opportunities and challenges in drug discovery," Current Topics in Medicinal Chemistry, vol. 6, no. 12, pp. 1303-1316, 2006.

[127] S. J. Steddon, N. J. Schroeder, and J. Cunningham, "Vitamin D analogues: how do they differ and what is their clinical role?" Nephrology Dialysis Transplantation, vol. 16, no. 10, pp. 19651967, 2001.

[128] G. D. Zhu, "Vitamin D analogs currently on the market and in development," in Why Does Vitamin D Matter? vol. 26, pp. 5782, Bentham Science Publisher, 2013.

[129] D. Feldman, J. Wesley Pike, and J. S. Adams, Vitamin D, Academic Press, London, UK, 3rd edition, 2011. 

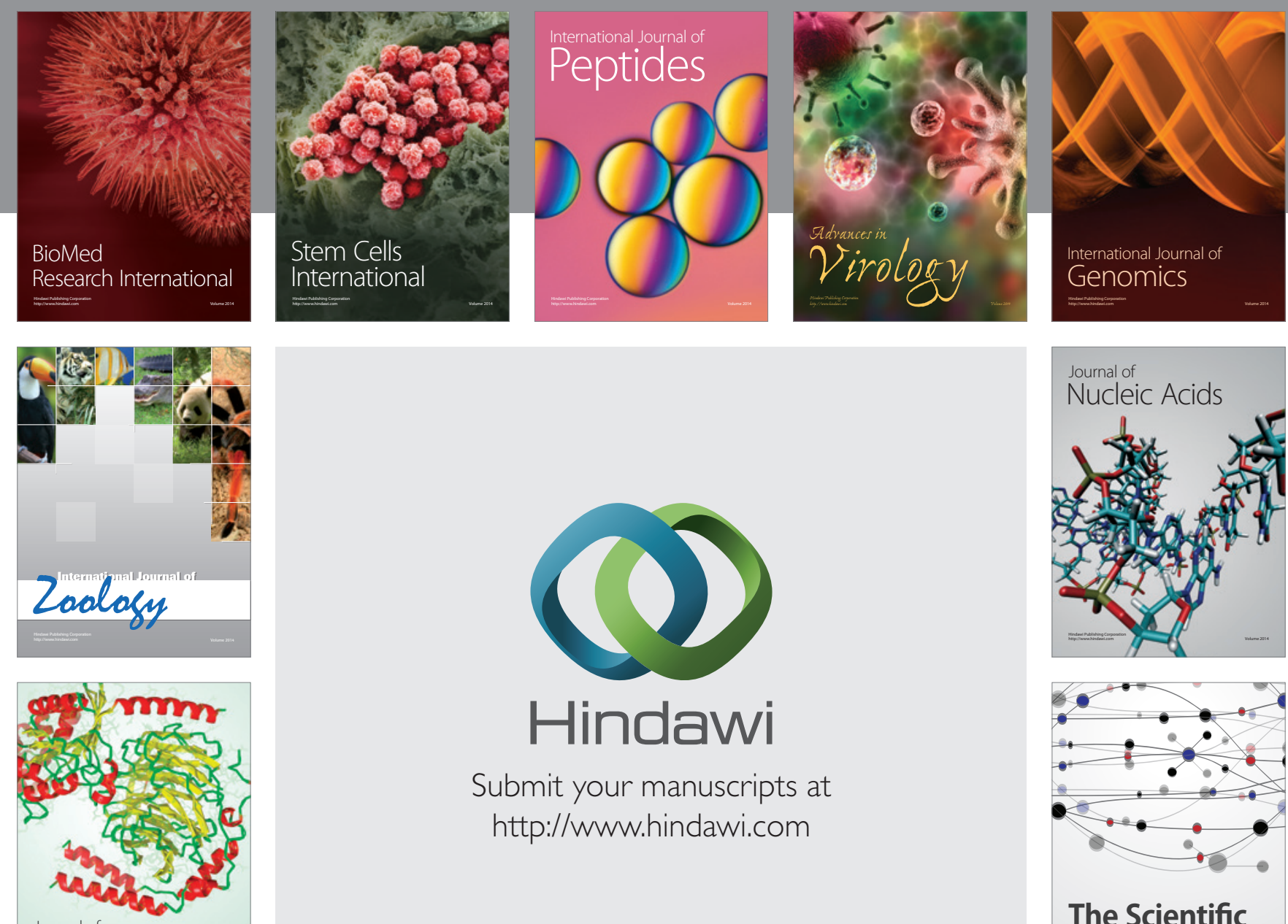

Submit your manuscripts at

http://www.hindawi.com

Journal of
Signal Transduction
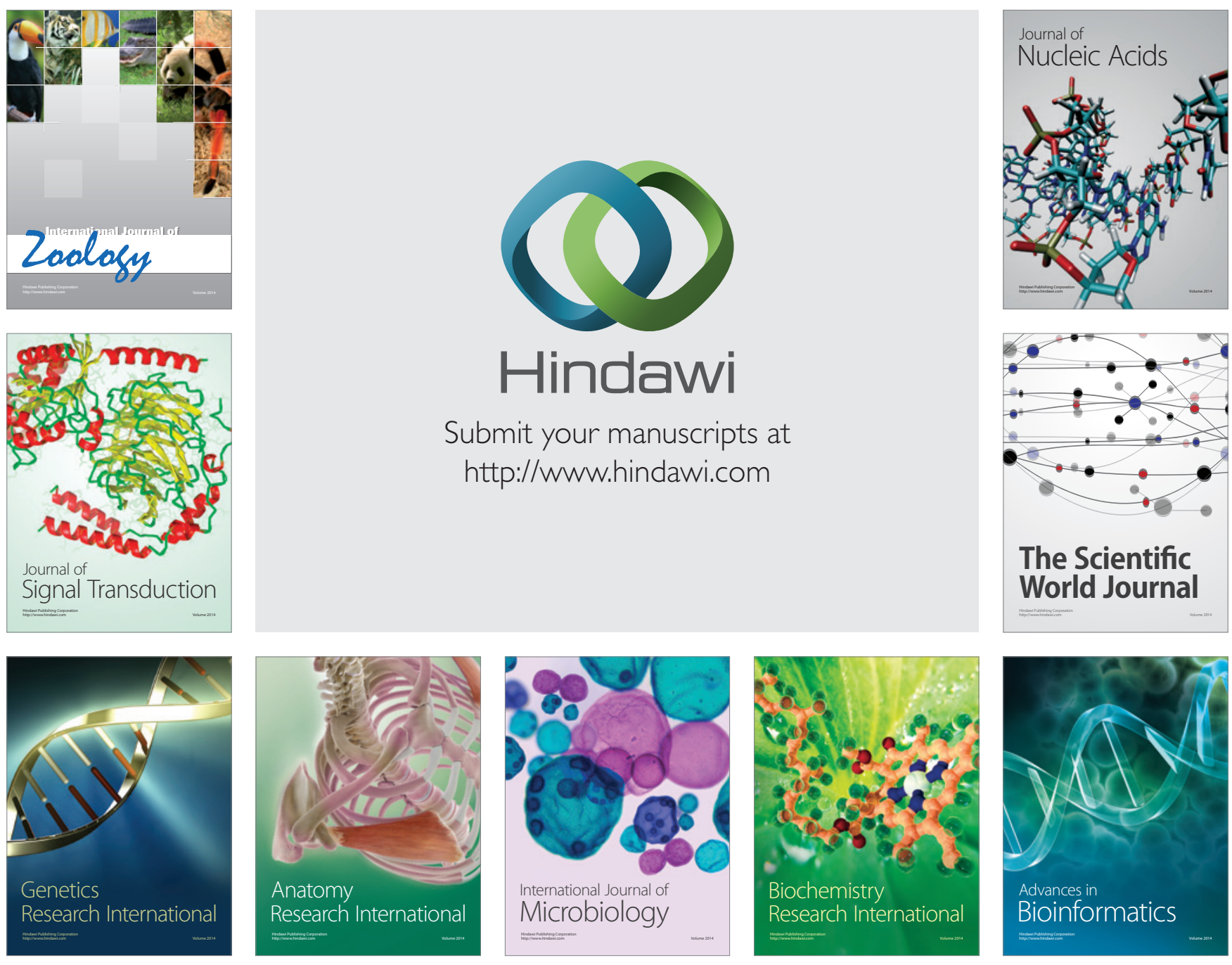

The Scientific World Journal
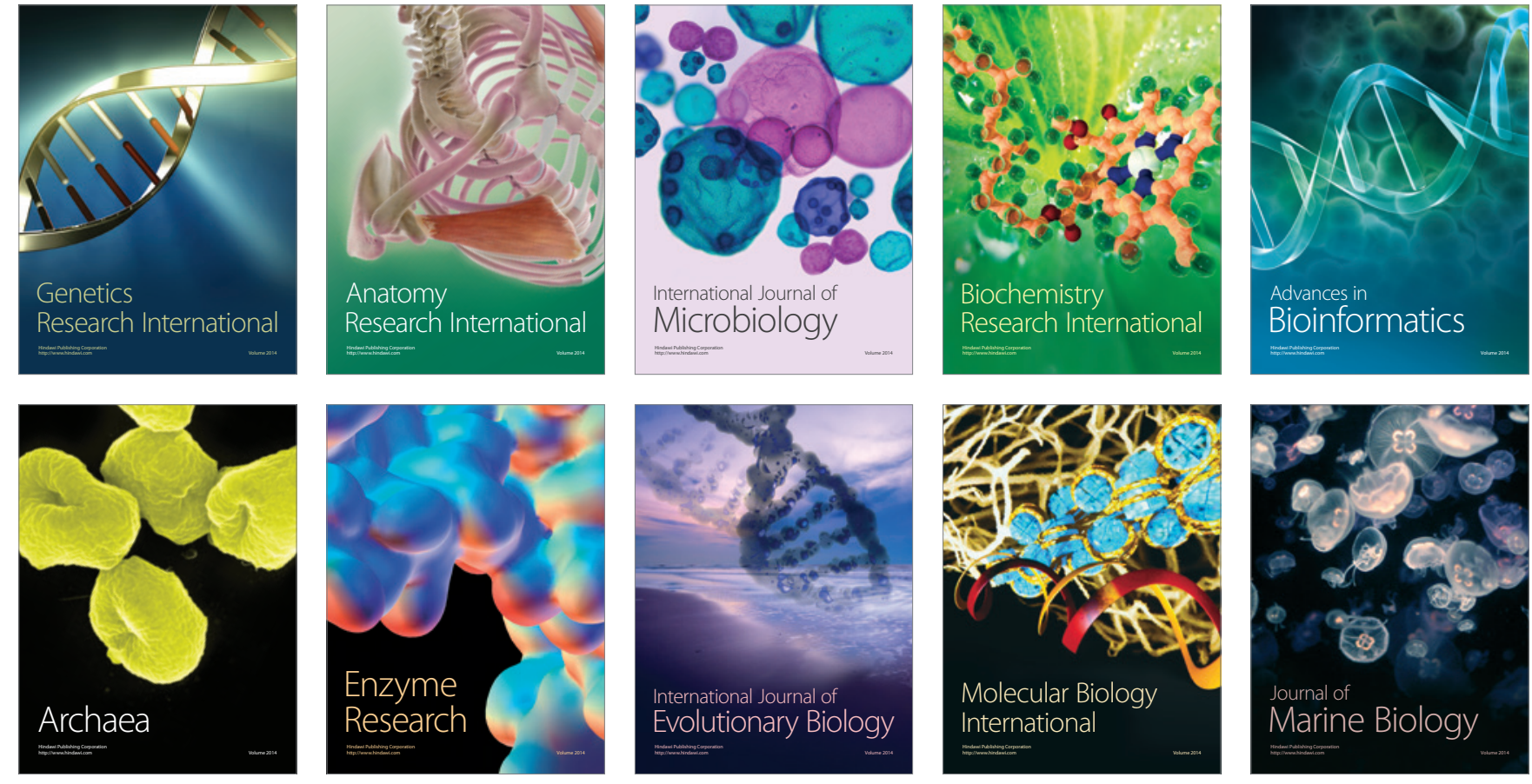